\title{
Optimization of Transport Routes by Fuzzy Logic Methods
}

\author{
Igor Olenych, Yurii Nechypor, Yurii Olenych \\ Department of Electronics and Computer Technologies \\ Ivan Franko National University of Lviv \\ Lviv, Ukraine \\ e-mail: iolenych@gmail.com
}

\author{
Andrii Gukaliuk \\ Department of Economics \\ Ivan Franko National University of Lviv \\ Lviv, Ukraine \\ e-mail: andrii.gukaliuk@lnu.edu.ua
}

\begin{abstract}
The fuzzy inference system of the Sugeno's type with four inputs and one output for the choice of optimal routes of the transport network is proposed in the work. The developed system involves the formation of a fuzzy production rules base, the fuzzification of the input parameters values, the aggregation of the sub-conditions truth of each rule, activating the conclusions and defuzzification the output variable. An algorithm for finding quantitative values of coefficients that corrects the weight of the graph edges in optimization problems under qualitative or approximate input data conditions is implemented. The proposed model of main roads of Ukraine network takes into account the condition of the road surface, the caution of transportation of cargoes, the traffic level and urgency of delivery during the formation of transport routes, which can improve the efficiency of the logistics system.
\end{abstract}

Index Terms - Transport routes, Fuzzy modeling, Production rules, Fuzzy sets

\section{INTRODUCTION}

Choosing the best routes and delivery schemes is an important task in the movement of products by vehicles occupies, which is solved through a comparative analysis of all possible options [1]. The use of innovative technologies and new IT tools, along with the transport infrastructure development and the integration of all functions of supply management, improve the logistics network economic efficiency [2-4]. Modeling is often used in research in the fields connected with planning and organization of transport logistics $[5,6]$. Usually, the classical optimization problems of the graphs theory are applied namely the problems of finding the shortest path and the minimal spanning tree [7]. But such algorithms do not take into account the additional influence of various factors that can change the weight of the edge in the graph. In addition, these factors may change over time, which requires a quick correction of the logistic system model.

Effective solutions in logistics systems require the consideration of many factors that are characterized by fuzzy information and approximation of the formal description, etc. [8]. In this case, it is advisable to use methods of fuzzy modeling. The fuzzy sets theory makes it possible to apply a linguistic description of weakly structured processes and formalize linguistic variables in decision making information systems [9-12].
In the present research, the model of the main roads of Ukraine network in the weighted graph form was developed. Specific attention was focused on modification of the optimization network algorithms by introducing corrective coefficients that take into account the parameters of the transport system and the conditions of transportation.

\section{MODEL DESCRIPTION}

Optimization of the transport system model is to introduce coefficients that correct the weight of the graph edges, depending on the road condition and the transportation caution, the traffic level and delivery urgency. In result, the minimum path $S$ will be determined not only by the weight of the $j$-edges of the graph $a_{j}$, which models the transport system, but also by the value of the corrective coefficient $k_{j}$, which reflects the transport conditions for each of the sections of the road network:

$$
S=\sum_{j} k_{j} a_{j} \rightarrow \min , \quad k_{j}>0
$$

The value of the corrective coefficient $k_{j}$ may be $<1$ when the resulting effect of all transportation conditions in the selected network segment $a_{j}$ decreases costs by a certain criterion, and vice versa $->1$, if such influence increases costs. Thus, depending on the parameters of the logistic system, the effective length of the transport network segment (i.e., the weight of the corresponding edge of the graph) may decrease or increase. The use of corrected data allows you to choose the best route.

The corrective coefficient can be determined by a linear combination of quantitative values of all parameters $x_{i}$ that influence on the cargoes movement in the $j$-segment of the transport network:

$$
k_{j}=\sum_{i} \varepsilon_{i} x_{i}
$$

where $\varepsilon_{i}$ - weight coefficients of each of the parameters $x_{i}$. The proposed model makes it possible to apply Sugeno's algorithm to calculate the corrective coefficients, according to 
which a linear combination of clear values of input variables forms the conclusion of each of the fuzzy production rules $[13,14]$. For this purpose it is necessary to form the base of the fuzzy rules in the form IF (condition) - THEN (action), to fuzzificate the values of the input parameters, to carry out the procedures for activating the conclusions and defuzzification of the output variable $[14,15]$.

\section{DESIGN OF FUZZY LOGIC SYSTEM}

In accordance with the proposed model, the fuzzy logic system of the Sugeno's type was developed with four inputs and one output. The setting of input linguistic variables "road conditions" = \{"bad", "satisfactory", "good" $\}$ and "level of caution" = \{"low", "high" $\}$, "traffic level"= \{"low", "middle", "high" $\}$ and "urgency" = \{"little", "great" $\}$ in plural $[0,10]$ allows experts to quantify the criteria of a transport system on a ten-point scale. Membership functions of fuzzy sets characterized the terms of the input variables "road conditions", "level of caution", "traffic level" and "urgency" were set by piecewise linear, as shown in Figure 1. The quantitative values of the transport system parameters can be fuzzificate by means of the set membership functions.

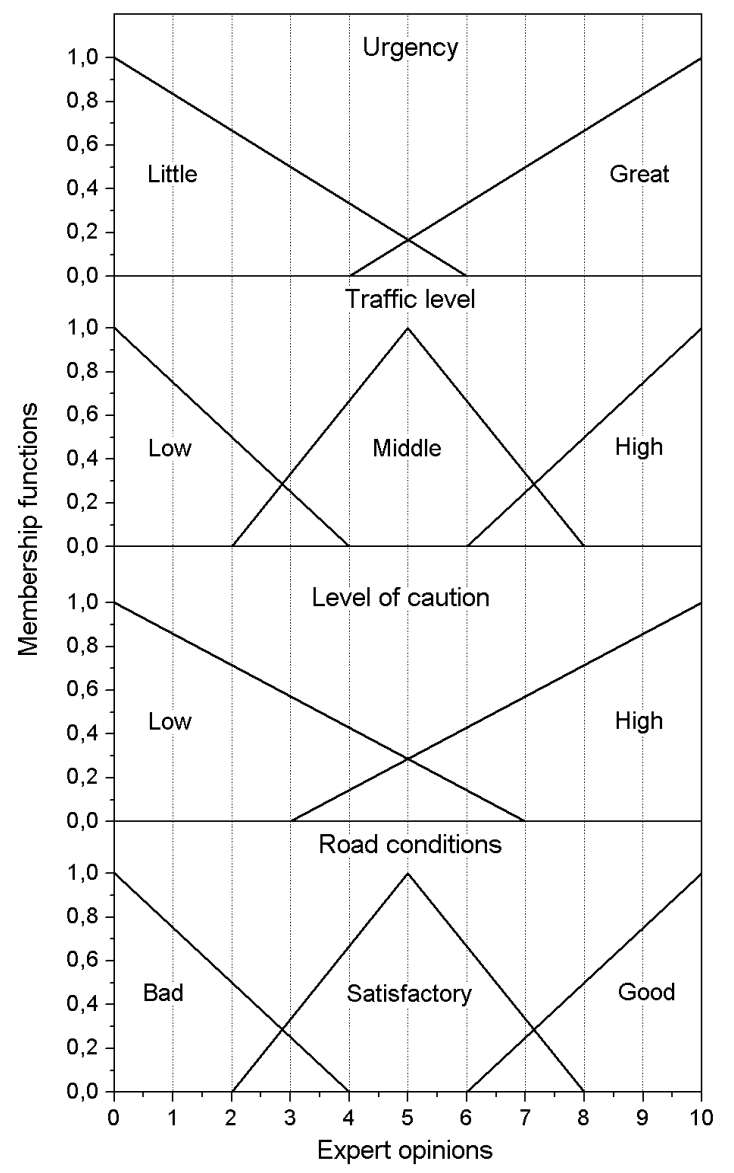

Figure 1. Membership functions of fuzzy sets characterized the terms of the input variables "road conditions", "level of caution", "traffic level" and "urgency".
The corrective coefficient $k_{j}$ for each edge of the graph can obtain as a result of activating the conclusions of fuzzy production rules $R^{(j)}$ :

$\boldsymbol{R}^{(\mathbf{1})}$ : IF bad road conditions AND great urgency THEN $w_{1}=1.5-0.05 x_{1}-0.02 x_{2}$;

$\boldsymbol{R}^{(2)}$ : IF satisfactory road condition AND great urgency THEN $w_{2}=1.4-0.04 x_{1}-0.025 x_{2}$;

$\boldsymbol{R}^{(\mathbf{3})}$ : IF good road conditions AND great urgency THEN $w_{3}=1.2-0.02 x_{1}-0.035 x_{2}$;

$\boldsymbol{R}^{(4)}$ : IF bad road conditions AND little urgency THEN $w_{4}=1.3-0.025 x_{1}-0.055 x_{2}$;

$\boldsymbol{R}^{(5)}$ : IF satisfactory road conditions AND little urgency THEN $w_{5}=1.2-0.02 x_{1}-0.05 x_{2}$;

$\boldsymbol{R}^{(\mathbf{6})}$ : IF good road conditions AND little urgency THEN $w_{6}=1.1-0.01 x_{1}-0.04 x_{2}$;

$\boldsymbol{R}^{(7)}$ : IF bad road conditions AND high level of caution THEN $w_{7}=1.4-0.04 x_{1}+0.03 x_{3}$;

$\boldsymbol{R}^{(\mathbf{8})}$ : IF satisfactory road conditions AND high level of caution THEN $w_{8}=1.05-0.04 x_{1}+0.02 x_{3}$;

$\boldsymbol{R}^{(\mathbf{9})}$ : IF good road conditions AND high level of caution THEN $w_{9}=1.0-0.025 x_{1}+0.01 x_{3}$;

$\boldsymbol{R}^{(\mathbf{1 0 )}}$ : IF bad road conditions AND low level of caution THEN $w_{10}=1.2-0.05 x_{1}+0.04 x_{3}$;

$\boldsymbol{R}^{(\mathbf{1 1 )}}$ : IF satisfactory road conditions AND low level of caution THEN $w_{11}=1.1-0.03 x_{1}+0.02 x_{3}$;

$\boldsymbol{R}^{(\mathbf{1 2 )}}$ : IF good road conditions AND low level of caution THEN $w_{12}=1.0-0.04 x_{1}+0.02 x_{3}$;

$\boldsymbol{R}^{(\mathbf{1 3})}$ : IF low traffic level AND great urgency THEN $w_{13}=1.0-0.03 x_{2}+0.05 x_{4}$;

$\boldsymbol{R}^{(\mathbf{1 4})}$ : IF middle traffic level AND great urgency THEN $w_{14}=0.95-0.02 x_{2}+0.04 x_{4}$;

$\boldsymbol{R}^{(\mathbf{1 5})}$ : IF high traffic level AND great urgency THEN $w_{15}=0.9-0.01 x_{2}+0.04 x_{4}$;

$\boldsymbol{R}^{(\mathbf{1 6})}$ : IF low traffic level AND little urgency THEN $w_{16}=0.95-0.03 x_{2}+0.02 x_{4}$;

$\boldsymbol{R}^{(\mathbf{1 7 )}}$ : IF middle traffic level AND little urgency THEN $w_{17}=1.0-0.025 x_{2}+0.015 x_{4}$;

$\boldsymbol{R}^{(\mathbf{1 8 )}}$ : IF high traffic level AND little urgency THEN $w_{18}=1.02-0.02 x_{2}+0.01 x_{4}$.

Here $x_{1}, x_{2}, x_{3}$ and $x_{4}$ are a quantitative assessment on a tenpoint scale of the road conditions, degree of urgency, caution and traffic level respectively.

Using the fuzzification procedure for the given values of the input variables, the degree of truth of the statements of each of the terms of the linguistic variables that formed the condition of the production rule was determined. As a result of the aggregation of subconditions verity in each of the fuzzy rules, the set $C=\left\{c_{1}, c_{2}, \ldots, c_{18}\right\}$ values of the truth condition of the rules of the system of the fuzzy inference was obtained. 
Since in the Sugeno's algorithm the conclusion of fuzzy rules is formed by a linear combination of the usual input values, therefore the value of the output variable is determined by a real number and there is no procedure for the accumulation of conclusions. The determination of the corrective factor ki was carried out by means of the defuzzification by the center of weight method for single-element sets [13]:

$$
k_{j}=\frac{\sum_{i=1}^{n} c_{i} w_{i}}{\sum_{i=1}^{n} c_{i}},
$$

where $n=18-$ number of fuzzy production rules. The application of the proposed algorithm for each section of the road network, which is characterized by its set of transportation parameters, allows determining the coefficients values that correct the weight of the graph edges of the logistic network.

\section{RESULTS AND DISCUSSION}

Figure 2 shows surface $k=f\left(x_{1}, x_{3}\right)$ input-output of the system of the fuzzy inference with fixed values of the traffic level and urgency of transportation.

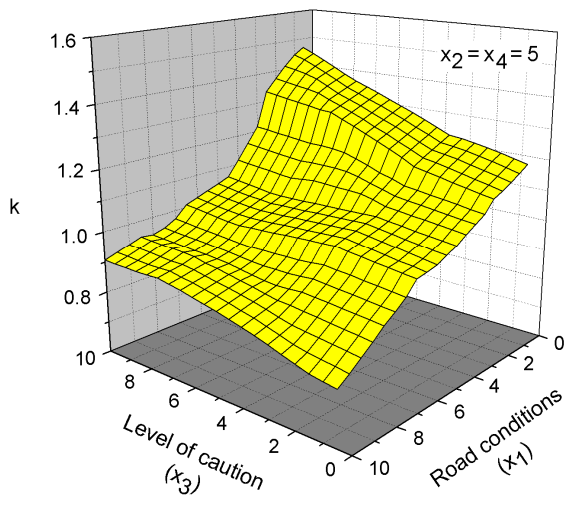

a

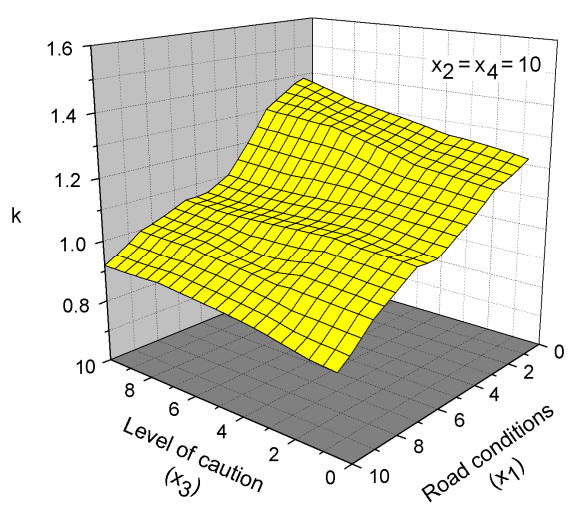

$\mathrm{b}$

Figure 2. Dependence of the correction coefficient on the road state and level of caution of the transportation at moderate (a) and high (b) traffic level and urgency of delivery.

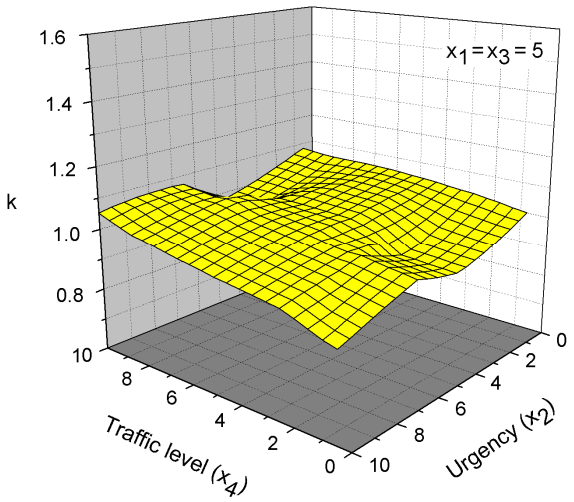

a

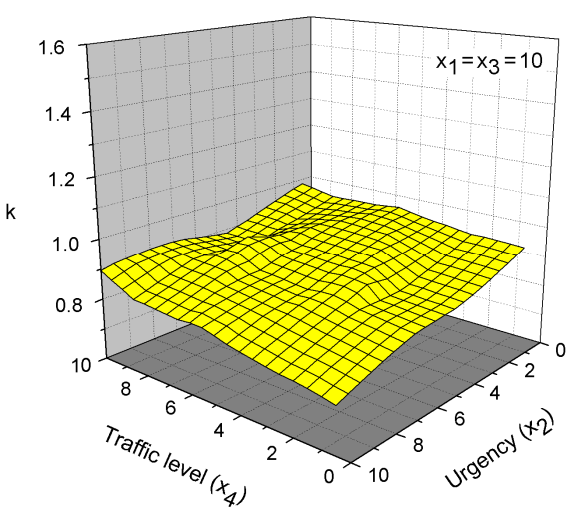

b

Figure 3. Dependence of the correction coefficient on the urgency and the traffic level with normal (a) and high (b) road conditions and level of caution of transportation.

The obtained results demonstrate that the bad condition of the road and high the level of transportation caution cause the increase of the correction coefficient for the selected transport network segment. The appearance of the surface $k=f\left(x_{1}, x_{3}\right)$ remains while increasing the level of traffic and urgency, but the change range of the correction coefficient decreases.

Visualization of the correction coefficient dependence on the urgency degree and traffic level in the form of surface $k=$ $f\left(x_{2}, x_{4}\right)$ has been revealed the reduction of the correction coefficient at high urgency and the low level of traffic for a good road condition (see Figure 3). However, the road conditions affect the correction coefficient to a greater extent.

To better visibility, the results of testing the system based on fuzzy logic for optimizing transport routes for different transportation conditions are shown in Table 1.

TABLE I. CORRECTION COEFFICIENTS OF THE TRANSPORT NETWORK MODEL

\begin{tabular}{|c|c|c|c|c|}
\hline $\begin{array}{c}\text { Road } \\
\text { conditions }\end{array}$ & $\begin{array}{c}\text { Level of } \\
\text { caution }\end{array}$ & $\begin{array}{c}\text { Traffic } \\
\text { level }\end{array}$ & Urgency & $\begin{array}{c}\text { Correction } \\
\text { coefficient }\end{array}$ \\
\hline 1 & 9 & 8 & 4 & 1.3512 \\
\hline 3 & 7 & 6 & 2 & 1.1516 \\
\hline
\end{tabular}


International Scientific and Practical Conference "Electronics and Information Technologies" (ELIT-2018)

\begin{tabular}{|c|c|c|c|c|}
\hline $\begin{array}{c}\text { Road } \\
\text { conditions }\end{array}$ & $\begin{array}{c}\text { Level of } \\
\text { caution }\end{array}$ & $\begin{array}{c}\text { Traffic } \\
\text { level }\end{array}$ & Urgency & $\begin{array}{c}\text { Correction } \\
\text { coefficient }\end{array}$ \\
\hline 5 & 3 & 10 & 9 & 1.0714 \\
\hline 7 & 5 & 2 & 7 & 0.8892 \\
\hline 8 & 10 & 7 & 4 & 0.9818 \\
\hline 9 & 6 & 1 & 8 & 0.7874 \\
\hline 2 & 4 & 3 & 1 & 1.1753 \\
\hline 4 & 2 & 4 & 10 & 0.9733 \\
\hline 6 & 1 & 9 & 3 & 0.97 \\
\hline 10 & 8 & 1 & 6 & 0.83 \\
\hline
\end{tabular}

The highest values of the factor are observed for parameters that characterize the bad road condition and the high degree of caution of the transportation, as well as high traffic level.

The proposed algorithm was tested on the model of the main roads network in Ukraine (see Figure 4).

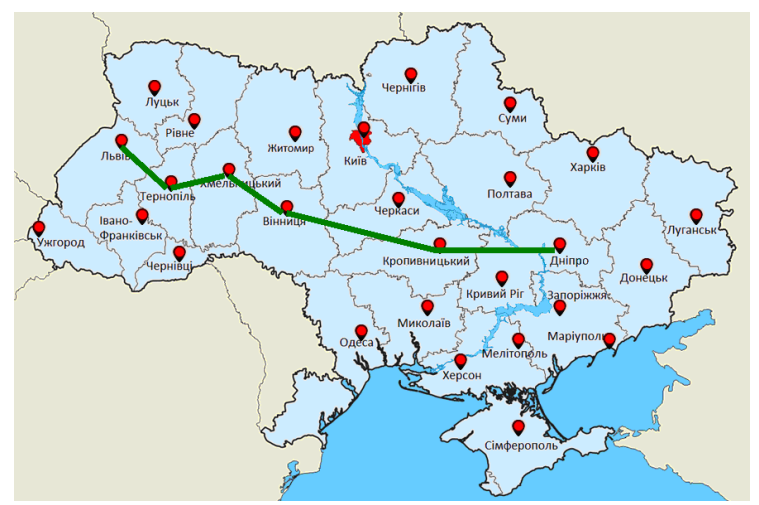

a

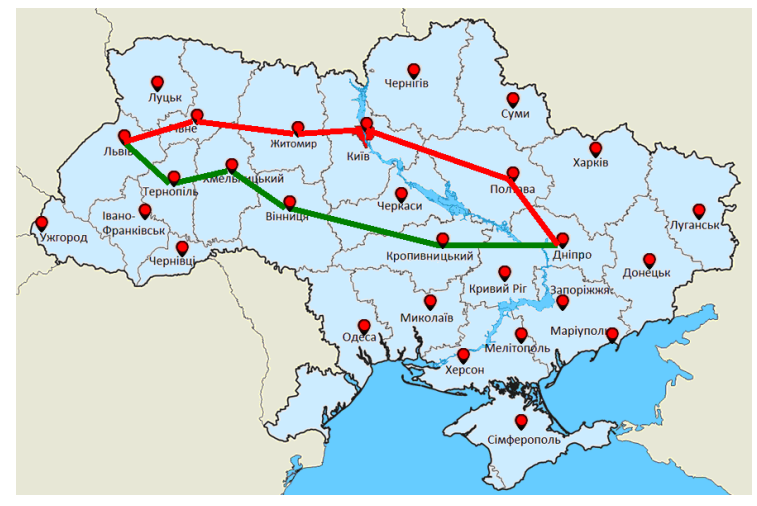

$\mathrm{b}$

Figure 4. Model of the main roads network in Ukraine. The optimal route before (a) and after (b) accounting of the transportation conditions.

Figure 4,a shows the minimum length route between two cities, determined using the Dijkstra's algorithm. After taking into account road conditions and other parameters of cargo transportation, computer calculations have identified the best

route with smaller "effective" length, which differed from the previous one (see Figure 4,b).

\section{CONCLUSIONS}

Considered in the work method of optimal transport routes formation with the help of systems of fuzzy inference of the Sugeno's type allows obtaining quantitative values of correction coefficients. On the basis of computer simulation, it has been established that presented system provides an increase in the weight of the edges of the graph in optimization algorithms for the formation of transport routes in the case of bad road conditions and high level of traffic or caution of transportation, and, conversely, reducing the weight of the ribs in the case of good road conditions, low traffic intensity or an increased urgency of transportation.

\section{REFERENCES}

[1] J. H. Bookbinder, and T. A. Matuk, "Logistics and Transportation in Global Supply Chains: Review, Critique and Prospects". Chapter 9 in Tutorials in Operations Research, M. Oskoorouchi, Ed., 2009, pp. 182211. DOI: $10.1287 /$ educ. 1090.0059 .

[2] R. L. Chapman, C. Soosay, and J. Kandampully, "Innovation in Logistic Services and the New Business Model: A Conceptual Framework", International Journal of Physical Distribution \& Logistics Management, vol. 33, pp. 630-650, 2003.

[3] S. J. Grawe, "Logistics Innovation: A Literature-Based Conceptual Framework", International Journal of Logistics Management, vol. 20, pp. 360-377, 2009.

[4] S. M. Wagner, "Innovation Management in the German Transportation Industry", Journal of Business Logistics, vol. 29, pp. 215-231, 2008.

[5] W. D. Kelton, "Methodological Expectations for Studies Using Computer Simulation", Journal of Business Logistics, vol. 37, pp. 82$86,2016$.

[6] A. M. Law, "Simulation Modeling and Analysis" 5rd ed., New York: McGraw-Hill, 2015.

[7] T. H. Cormen, C. E. Leiserson, R. L. Rivest, and C. Stein, "Introduction to Algorithms" 3rd. ed., MIT Press, 2009.

[8] I. B. Olenych, and A. F. Gukaliuk, "Application of the Fuzzy Modeling for Optimization of Transport Routes", Universal Journal of Computational Mathematics, vol. 5, pp. 87-92, 2017.

[9] L. A. Zadeh, "Fuzzy Sets", Information and Control, vol. 8, pp. 338353, 1965.

[10] I. B. Olenych, "Fuzzy Logic Controller for Smart Home Lighting Control", Information and Telecommunication Sciences, vol. 9, pp. 50$55,2017$.

[11] V. Kumar, S. Kumar, and H. Kansal, "Fuzzy logic controller based operating room air condition control system", International Journal of Innovative Research in Electrical, Electronics, Instrumentation and Control Engineering, vol. 2, pp. 510-514, 2014.

[12] S. M. Sobhy, and W. M. Khedr, "Developing of Fuzzy Logic Controller for Air Condition System", International Journal of Computer Applications, vol. 126, pp. 1-8, 2015.

[13] T. Takagi, and M. Sugeno, "Fuzzy Identification of Systems and Its Applications to Modeling and Control", IEEE Transactions on Systems, Man and Cybernetics, vol. 15, pp. 116-132, 1985.

[14] T. Terano, K. Asai, and M. Sugeno. "Fuzzy Systems Theory and Its Applications", London: Academic Press, 1992.

[15] Y. Bai, and D. Wang, "Fundamentals of Fuzzy Logic Control - Fuzzy Sets, Fuzzy Rules and Defuzzifications", in Advanced Fuzzy Logic Technologies in Industrial Applications, Springer, 2006, pp. 17-36. 